\title{
Sustainable smart forest monitoring system for burning forest and deforestation detection
}

\author{
Denny Darlis ${ }^{1, *}$, Dion Saputra Parulian Sirait ${ }^{2}$, and Dimas Bayu Maulana ${ }^{1}$ \\ ${ }^{1}$ Telkom University, Diploma of Telecommunication Engineering, Jl. Telekomunikasi, Bandung, Indonesia \\ ${ }^{2}$ Telkom University, School of Electrical Engineering, Jl. Telekomunikasi, Bandung, Indonesia
}

\begin{abstract}
Forests sustain the planet and provide air, soil, climate cycles. These ecosystem services enable economic sectors. Forests are under threat, last decade about 13 million of hectares of forests were deforested. A system to provide monitoring and prevention are needed to sustain the forest but only a few countries have implemented a smart forest system alike. By utilizing sensors, minimum wireless system and renewable energy will provide more accurate, real time, efficient energy and easy to maintain compare to the conventional conservation. Our proposed system will consist of low power camera and grid of fire and smoke detectors, humidity and temperature sensors connected each other as a mesh network and each powered by a solar panel and lithium battery processed by microcontroller then send data periodically to the monitoring server and gives precaution information when some case happened. The system use environment disguise and periodically maintain to ensure it works. While precaution information can be shared and access by government or even public, human act are needed to solve it. Thus it could assist the already implemented system and utilize the available resources as possible.
\end{abstract}

\section{Introduction}

Forests always become an important area on earth which sustain the planet and provide the living life's needs such as air, soil, and climate cycles. But since 1973, for example, according to some data at Borneo island, about 13 million of hectares of forests were deforested as shown on Fig.1. Forest fires are often only discovered after a fire that burns land or gardens is widespread or has burned out and leaving a thick smoke. This certainly

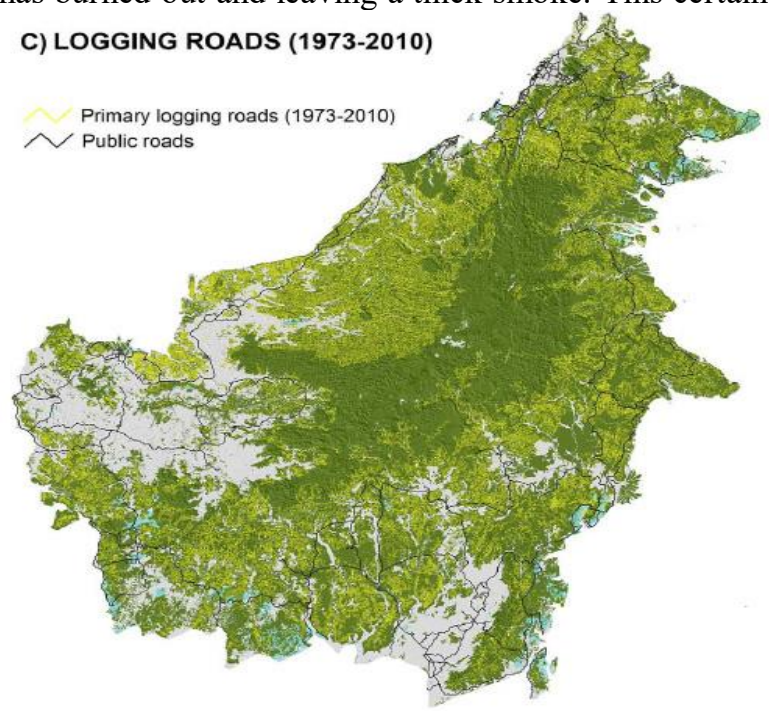

resulted in economic losses for people whose land is burned, and bad for the health of residents who inhale the smoke of forest fires [1]. Therefore, the solution is to use wireless sensors as monitoring and fire detection as an early prevention of forest fire indication. Using a wireless sensor can minimize the cost incurred compared to using a wired sensor so that more efficient against the extent of forest to be reached by the sensor.

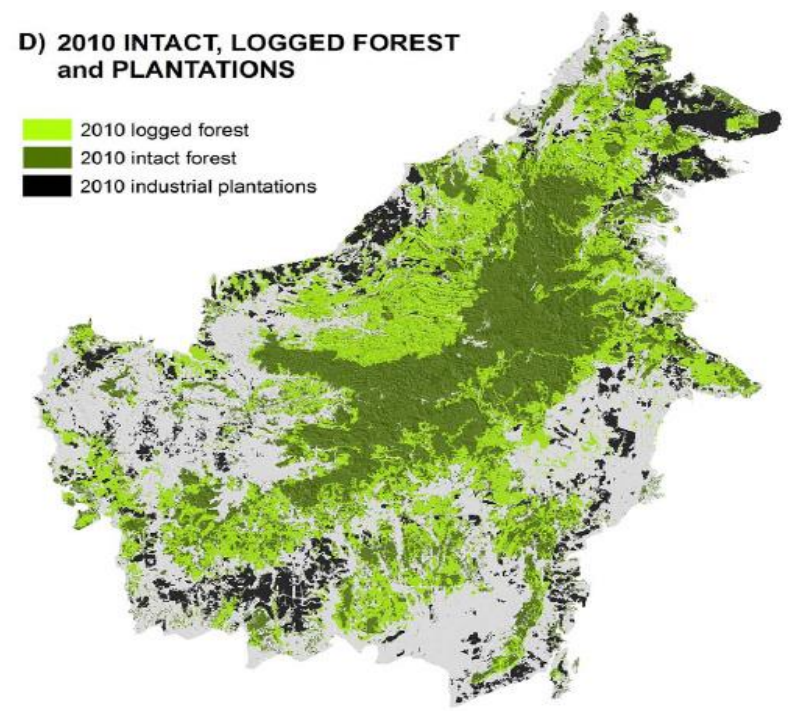

Fig. 1. Deforestation in Borneo island since 1973 (source: https://news.mongabay.com/2014/07/30-of-borneos-rainforests-destroyedsince-1973/)

\footnotetext{
* Corresponding author: denny.darlis@tass.telkomuniversity.ac.id
} 
By using Wireless Sensor Network (WSN) system to overcome the problem of forest area so it is possible to collect data from changes of sensors caused by fire from certain points [2]. From the sensor, the data obtained will be forwarded to the microcontroller, then send the data through a web-based network to the PC user.

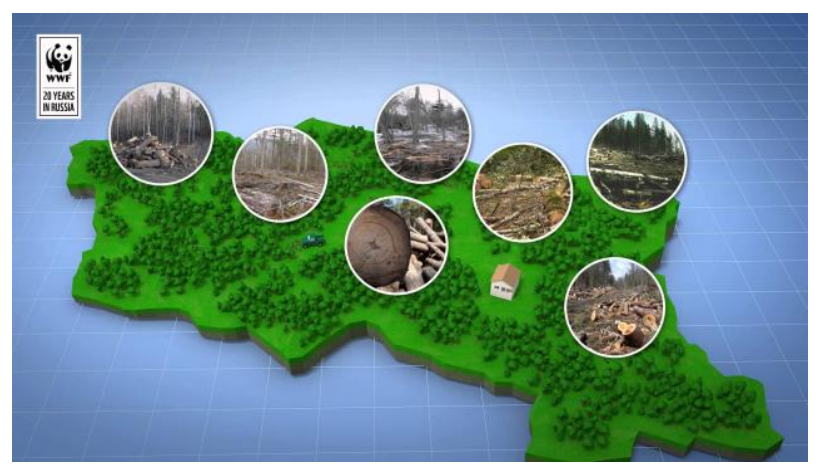

Fig. 2. Example of forest monitoring using Internet of Things (source:https://www.youtube.com/watch?v=gBLKEKbgL80)

In this study, sensor node system can be operated for several hours with high accuracy. The temperature sensor targeting to produce error only $0,5^{\circ} \mathrm{C}$. The maximum transmission distance of the node sensor data with the gateway node is seven meters. And for with this sensor arragement it takes nine minutes for the sensor to be able to detect fire after the first time it is activated.

\section{System design}

In the process, this system uses the basic concept of Wireless Sensor Network (WSN) which consists of three monitoring nodes and one node sink. The monitoring node consists of several hardware that helps the system work such as the battery as a power source, the DHT11 sensor as device that measures the ambient temperature of the environment around the node[3]-[4],[5], the MQ4 sensor measures the smoke thickness content around the node[6]-[7], the Arduino Pro Mini as the core of all systems working in the set work of all existing hardware[8]-[9], NRF24L01+ module as a wireless sender and receiver of data already obtained as shown on Fig.2. In the sink node section consists of arduino Uno, NRF24L01 module, and ESP 8266 as WiFi module that helps the system in sending the results of data to web monitoring [10]-[12].

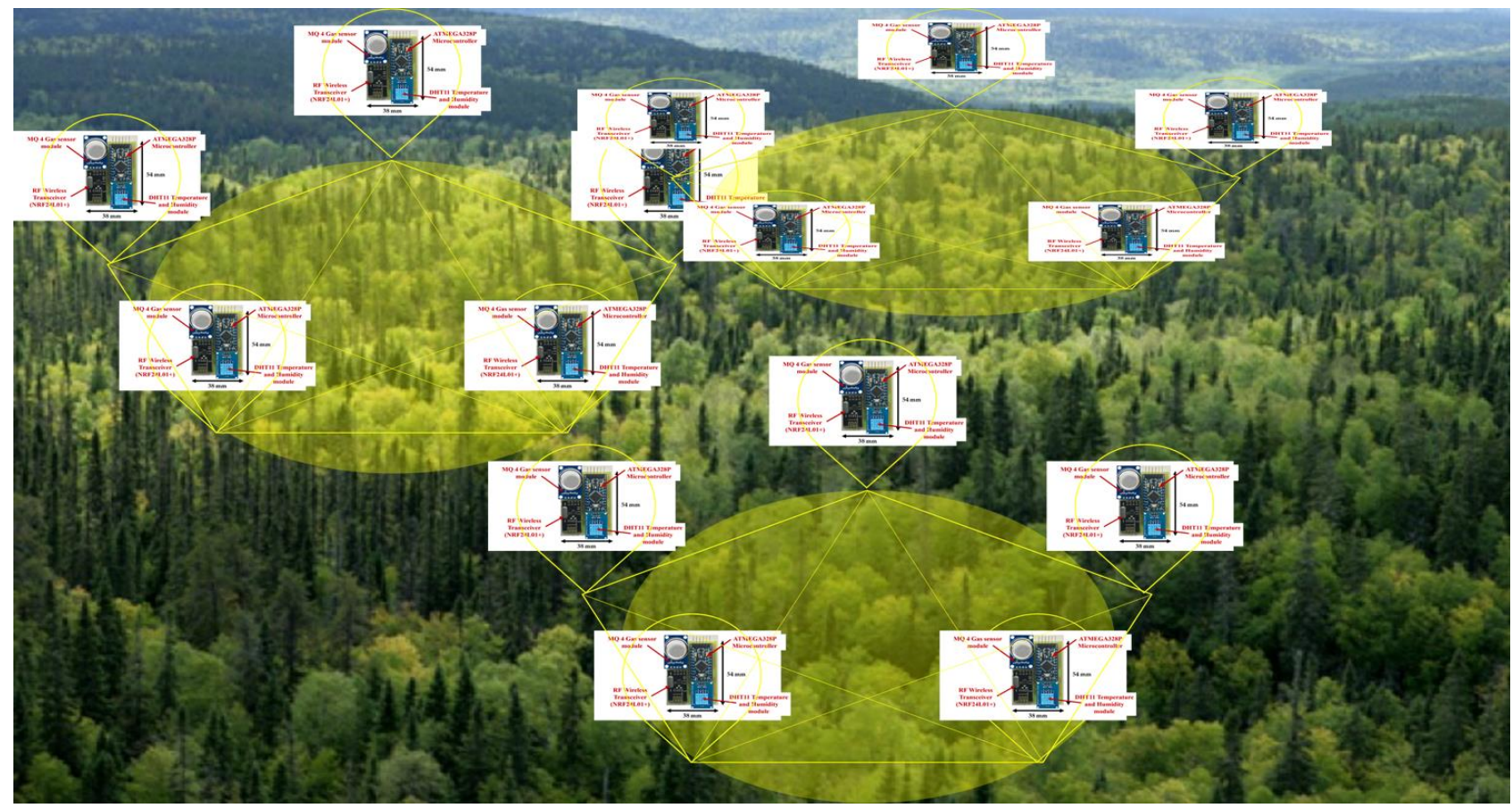

Fig. 3. Wireless Sensor Network for forestation and deforestation monitoring system with node prototype shown on Fig.5.

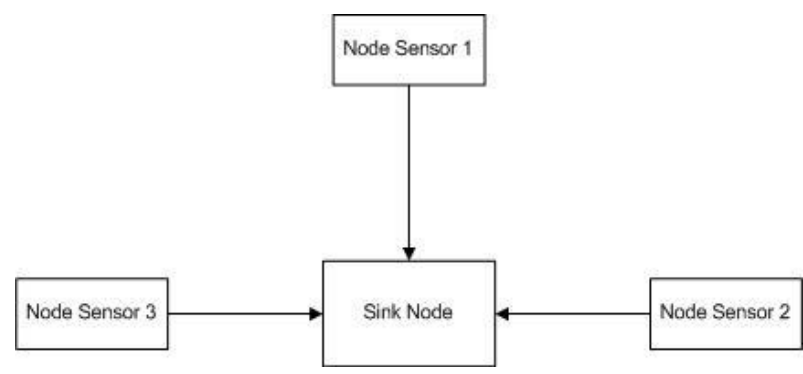

This system applies the concept of Wireless Sensor Network where in the data transmission of monitoring results by the sensor will be sent wirelessly to minimize the use of cables so that more efficient and cost-effective design. In the design is used star topology where there is a sink node that became the center of the sensor node. In the implementation is realized in the form of providing a sink node as the central node (gateway), to then all other sensor nodes connected to the gateway node.

Fig. 4. Node sensor topology. 


\section{Implementation}

Here is the working principle of monitoring system that starts from the work of the sensor to the end of the system ie the web. The first thing to do is activate all the tools until the database sender device is connected to the monitoring website. Then the sensor device will work to take temperature data for the DHT11 sensor and carbon monoxide gas content data for the MQ4 sensor. Once the data is obtained by each sensor node, then the data will be processed by atmega 328 contained in arduino promini to process through the program that has been given. Through the processing result will get temperature temperature $\left({ }^{\circ} \mathrm{C}\right.$ ) and carbonmonoksida gas content (ppm) which will be forwarded to sink node then sent to website monitoring through internet network to be monitored by user.

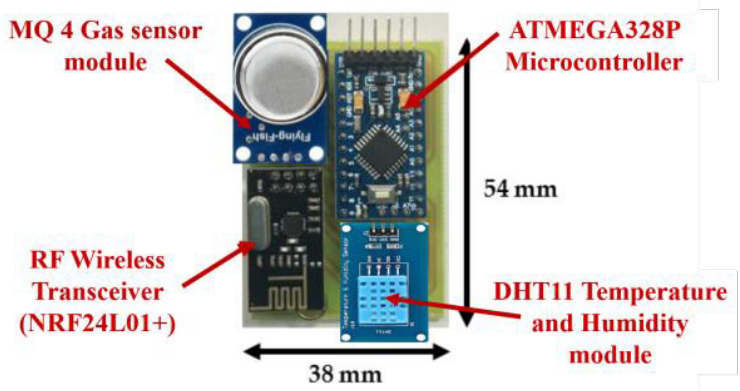

Fig. 5. A wireless sensor node prototype for forest system monitoring.

\section{Results and discussion}

Test results during artificial firing around the sensor node. Manipulation of environmental conditions to see the work of sensor detection by making the burning smoke of paper on the three nodes in turn. From the test results data obtained at the time of smoke detection there is an increase in the amount of gas content detected by the sensor which is marked by increasing the ppm content of carbon monoxide gas which can be seen from Fig.6.

\section{- ESP NETWORK 0 角 $\mathrm{i}$}

\begin{tabular}{|l|l|}
\hline ESP01 & Current Output \\
\hline Attribute Name & 30.1 \\
\hline Node 1 Temperature & 200 \\
\hline Node 1 Gas & 31.1 \\
\hline Node 2 Temperature & 200 \\
\hline Node 2 Gas & 30.7 \\
\hline Node 3 Temperature & 200 \\
\hline Node 3 Gas & 6069 \\
\hline Detik ke & \\
\hline Add More Device & \\
\hline
\end{tabular}

Fig. 6. Web synchronized data between sensor and sink node.
In Fig. 6 a cloud application based on web called Geeknesia is used to monitor the detected data from each sensor node. Where in it can be seen temperature and gas data from each node. Geeknesia web also provides a database where the displayed data will be stored and can be viewed in graphical form. Wireless Sensor Network for forestation and deforestation monitoring system can see in fig. 7.

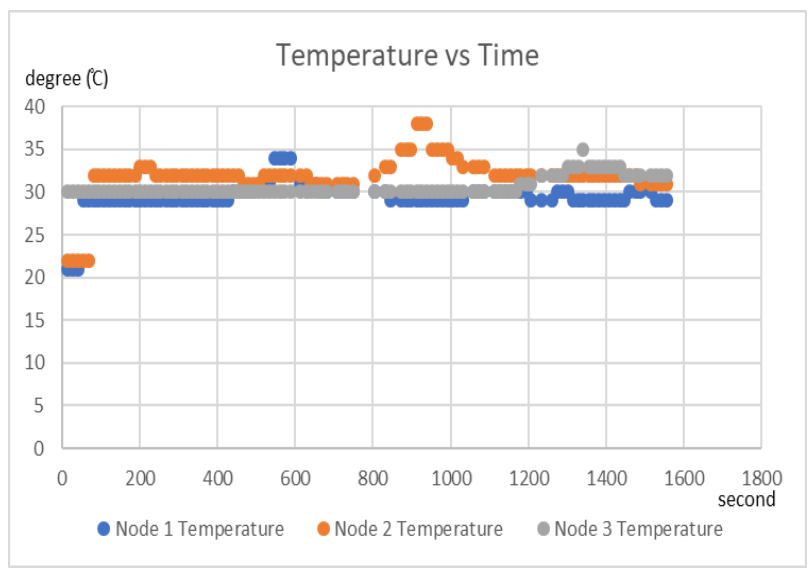

Fig. 7. Wireless Sensor Network for forestation and deforestation monitoring system.

In comparison the three sensor nodes at a distance of seven meters visible node sensor temperature 1 start stable in seconds to 60 while node 2 at seconds to 100 . Node 3 has been stable since it was first activated. When the smoke response is given, the temperature sensor node 1 experiences a temperature rise of 100 seconds at 500 to 600 seconds. The temperature sensor node 2 has the highest temperature rise reaching $38^{\circ} \mathrm{C}$ for 250 seconds. While the temperature node 3 for 300 seconds can reach a maximum point of $35^{\circ} \mathrm{C}$. Output voltage of 2 until 20 pcs piezoelectric transducer in parallel connection mounted below the floor tile prototype can see in fig. 8.

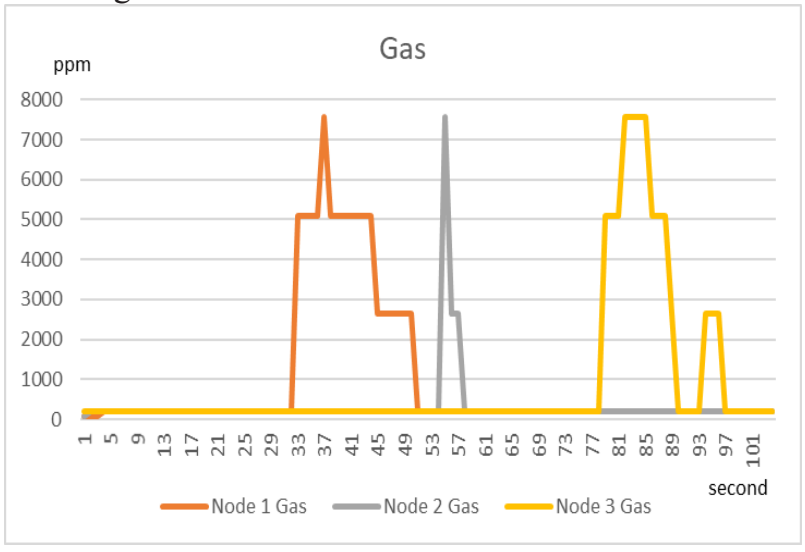

Fig. 8. Output voltage of 2 until 20 pcs piezoelectric transducer in parallel connection mounted below the floor tile prototype.

The results of monitoring the three gas sensors at a distance of seven meters visible carbon monoxide gas content does not reach the maximum point of $10000 \mathrm{ppm}$ which only reached $7550 \mathrm{ppm}$. The sensor node 1 detects the gas content around the node for 200 seconds while at 
the sensor node 2 detects the fastest gas content for only 40 seconds. At the sensor node 3 detects carbonmonoxide content for 200 seconds.

From the measurement graph by all three sensors as a whole, obtained when the MQ4 smoke sensor detects high carbon monoxide content, the temperature sensor also experiences an increase in temperature. It can be concluded that the three sensor nodes can work well to detect changes in temperature conditions and gas contents that could potentially cause a fire.

\section{Conclusions}

From the results of tests that have been done Implementation of Wireless Sensor As Monitoring and Detector of Forest Fire Indicator, can be drawn conclusions with the required power of $0.5 \mathrm{~A}$ on each sensor node and the capacity of the battery used $2000 \mathrm{mAh}$ then the endurance of the node sensor after activation can last until the battery is discharged for about four hours. The condition of the MQ4 sensor after it is activated can be said to be stable 200ppm (normal air condition) on Node 1 is after 5 minutes 44 seconds, at Node 2 after 8 minutes 12 seconds and Node 3 after 9 minutes 4 seconds. The maximum transmission distance of the data by the sensor node to the gateway node is seven meters.

Authors would like to thank School of Engineering and School of Applied Sciences, Telkom University for supporting materials and facilities in this research.

\section{References}

1. Adinugroho, W. C.. Bagaimana Kebakaran Hutan Terjadi. hal. 6. April 20 (2012)

2. I Putu Agus Eka Pratama, Sinung Suakanto. Wireless Sensor Network (WSN) Teori dan Praktik Berbasiskan Open Source. (Informatika Bandung, Bandung, 2015)

3. Hendy, C. Komunikasi antar Arduino dengan nRF24L01. (Online) available at: christianhendy.blogspot.co.id/2014/04/arduino-dannrf24101-radio.html, April (2014)

4. Henry. LM35 Arduino Temperature Sensor User Manual. (Online) available at: http://henrysbench.capnfatz.com/henrysbench/arduino-temperature-measurements/lm35arduino-temperature-sensor-user-manual/ (2009)

5. Incorporated, T. I. LM35 Precision Centigrade Temperature Sensors. (Texas Instruments, Texas, 1999)

6. Praveen. LPG sensor using arduino. (Online) available at: Circuits Today: www.circuitstoday.com/lpg-sensor-using-arduino, November (2014)

7. Rydepier. MQ4 Gas Sensor and Arduino. (Online) available at: Rydepier: https://rydepier.wordpress.com/2015/07/02/mq2gas-sensor-and-arduino/, Juli (2015)
8. Harding, D. Programming Arduino Pro Mini with Bus Pirate. (Online) available at: blog.oneharding.com/programming-arduino-promini-with-bus-pirate/ (2004)

9. HENDRI, S. Arduino Uno. (Online) available at: http://belajar-dasarpemrograman.blogspot.co.id/2013/03/arduinouno.html, Februari 08 (2016)

10. SA, N. S. Nordic Semiconductor. Single chip 2.4 GHz Transceiver NRF24L01, (Online) available at: http://www.nordicsemi.com/eng/Products/2.4GHzRF/nRF24L01, Maret (2016).

11. Cia, A. e. Connect the Arduino in wireless 802.11 network with ESP8266 module. (Online) available at: www.arduinoecia.com.br/2015/03/arduinomodulo-wireless-esp8266.html, Maret (2015).

12. Hamblen, J. Using the ESP8266 to add Wi Fi to the mbed LPC1768. (Online available at: developer.mbed.org/users/4180_1/notebook/usingthe-esp8266-with-the-mbed-lpc1768/ (2016) 